\title{
RETRACTED ARTICLE: Blepharoptosis Correction by Excision of the Levator Muscle and Tarsus in Chinese Patients
}

Liu Tianyi · Shen Haiyan · Liu Fei •

Yang Qun · Qian Yunliang • Dong Jiasheng •

Yang Jun

Received: 3 November 2009/ Accepted: 8 March 2010/Published online: 20 May 2010

(c) Springer Science+Business Media, LLC and International Society of Aesthetic Plastic Surgery 2010

This article has been published OnlineFirst, but is withdrawn due to prior publication in a competing journal.

This article has been published OnlineFirst, but is withdrawn due to prior publication in a competing journal.

L. Tianyi · S. Haiyan · L. Fei · Y. Qun · Q. Yunliang ·

D. Jiasheng · Y. Jun $(\bowtie)$

Department of Plastic and Reconstructive Surgery,

Shanghai 9th People's Hospital, Shanghai Jiaotong University,

Zhizaoju Road No. 639, Shanghai 200011, China

e-mail: y_j_55569@yahoo.com.cn

Present Address:

L. Tianyi

Department of Plastic and Aesthetic Surgery, Hua Dong

Hospital, Fu Dan University, Shanghai, China 